\title{
The issues of the process of evidence collection during preliminary investigation in the Republic of Tajikistan
}

\author{
Aleksei Parfenov* \\ Faculty of Law, Russian-Tajik (Slavonic) University, M. Tursunzoda str., 30, Dushanbe, 734025, Tajikistan
}

\begin{abstract}
This paper addresses the topical issues that arise in the process of preliminary investigation and initial operations and investigations related to collecting and obtaining evidence. In particular, the study raises the problematic questions about the nature and goals of technical and criminalistic support of the forensic experts' research activities during crime scene investigation while specifying relevant statistical data. The author provides an analysis of the state of usage of the forensic equipment employed in obtaining and collecting evidence during crime scene investigation during preliminary investigation in the Republic of Tajikistan and other countries. The paper also covers the issues of knowledge, skills, and abilities of the subjects collecting and obtaining evidence for criminal cases and determines the requirements to to the knowledge, skills, and abilities of the forensic experts who participate in crime scene investigation. Keywords: evidence, criminal investigation, crime scene investigation, evidence.
\end{abstract}

\section{Introduction}

Continuing the research of the problems of the process of collecting and obtaining evidence in the present-day conditions of the Republic of Tajikistan, it is necessary to note that the gradually rising demands of the investigative practice and together with them the growing possibilities of the developing progress in science and technology to satisfy such demands [1] conditioned the emergence of such scientific category in forensics in the 1980s as the forensic support of law enforcement activities for investigating and solving crimes [2, 3].

In legal proceedings, it is traditional to assume that evidence represents the process of establishment of truth during the procedure and learning and substantiation of the concepts of its content. "The nature of this process lies in collecting, studying, evaluating, and using evidence, and in terms of activity, it represents the unity of cognitive and certifying aspects [4].

Collection and studying of evidence at the stage of preliminary investigation in the Republic of Tajikistan is carried out through investigative activities and other procedural actions, whose list and procedure is specified in the Code of Criminal Procedure of the Republic of Tajikistan [5] (hereinafter CCP RT), as well as on the basis of the materials obtained by the appropriate agencies in the course of initial operations and investigations. Once obtained, evidence is evaluated and used at the stage of preliminary investigation, according to Part 1 Art. 88 of the CCP RT, by investigators and interrogators who exercise the law and their legal awareness, evaluate the evidence according to their inner conviction based on the complete, comprehensive, and objective consideration of all merits of the case from the point of view of the relevance, admissibility, and sufficiency of all collected evidence in their totality to solve the criminal case [5] based on the rules of evidence evaluation.

When considering initial operations and investigations as a stage of preliminary examination of a report of a crime, it is necessary to point out that "initially it is aimed not only at obtaining the data necessary to prepare and carry out investigative actions and identifying elements of offence (which become the reason for instituting criminal proceedings) but also at solving the crime, that is at obtaining the data that confirm the fact of committing the crime and the information about the culprit [6]. In this regard, the requirement of admissibility of such evidence is an important guarantee of fair trial expressed in the conformity of such evidence to the regulatory requirements of the criminal procedure legislation. Together with other criteria (of relevance and sufficiency), this criterion ensures sufficient conditions for the admission of information as evidence for the case. Departure from the established provisions of law can lead to the inadmissibility of evidence, its legal invalidation, and loss of the ability to use it in the process of proving.

Taking this into account, the respective results in their quantification can be evaluated in comparison by periods of time, between internal affairs agencies of different districts and provinces of the Republic of Tajikistan, by type of investigated crimes, and, finally, between other countries.

* Corresponding author: parfenov_alexey@mail.ru 


\subsection{Problem Statement}

The conditions of constant readiness can be assessed with respect to the state of legal, organizational, and scientific and technical support of forensic activities on a crime scene. For example, it is unlikely that such readiness is ensured by the inconsistent and contradictory regulations of the use of forensic equipment to collect and study evidence in the Code of Criminal Procedure of the Republic of Tajikistan [5]: the absence therein of the principle of admissibility of such equipment; the statement of the order of recording the results of its use not in the overall process of investigation or when carrying out all investigative activities (which follows from Part 3 Art. 171 of the CCP RT), but only for some of them (for example, in Art. 200 of the CCP RT describing the content of a record of interrogation); the uncertainty of the order of assigning, execution, and legal assessment of expert opinion (which is mentioned as a type of evidence in Art. 72 of the CCP RT, however, is not mentioned anywhere else) and the expert's responsibility for issuing false evidence. A similar issue is the currently archaic prohibition for forensic investigators to carry out examinations if they have already acted as experts in this case (Art. 67 Pt. 3 of the CCP RSFSR [7]).

We consider rather illogical the opinion of certain authors who, with reference to Part 4 Art. $88^{1}$ CCP RT, i.e. "to that the evidence recognized as inadmissible is considered invalid and can not serve as a basis of a charge", proceed to actively assert at various levels that the unduly obtained evidence can not be used to substantiate a charge but can be used to substantiate the merits acquitting the defendant.

\subsection{Purpose of the Study}

These considerations raise the question of whether all violations of law should entail the inadmissibility of evidence and its legal invalidation? Processualists give an affirmative answer: any evidence obtained with a breach of law should be considered inadmissible [8]. Unfortunately, these days it pretty often happens so that important items found on the scene of a crime that are substantial for resolving a case on its merits are considered unduly obtained and, consequently, excluded from the list of evidence. This leads to the defendant's acquittal [8].

\subsection{Research Methods}

The methodological foundation of this research are general and particular scientific methods: comparative legal, structural-systematic, specific sociological, formal logical, and logical legal methods as well as the methods of statistical analysis and generalization. Other methods applied were analysis, synthesis, induction, and deduction along with observation, comparison, and simulation.

\section{Results and Discussion, Findings}

We believe that the content of the process of collecting data about the information that has evidential value can be conditionally supplemented by the following information divided into three significant blocks (stages of obtaining information):

Block A: obtaining information about the evidential value of the materials, i.e. carrying out the preinvestigation check. This can include the following materials: testimonies obtained from participants of a crime and eyewitnesses; protocol of crime scene investigation with the analysis of material evidence on the scene; individual materials of the initial operations and investigations carried out prior to the institution of criminal proceedings.

This block of information directs both the investigator and the operative working to solve this crime and, as a rule, supporting its further investigation, in terms of the main directions collecting and registering the evidence information that has forensically significant value (its significance is conditioned by the expeditiousness of evidence collection; completeness based on, first of all, emotions of the participants of the procedure; lack of time to prepare for collecting and registering the obtained evidence; ensuring the safety of the obtained evidence, especially the most significant ones).

Missing here is the stage of preliminary investigation and clear and specific regulation of preliminary proceedings, which "logically leads to the conclusion that if the procedure of collecting evidence for pre-trial and out-of-court proceedings is almost not regulated, it is impossible to contravene it" [9].

That is why it appears logical to conclude that all information collected in the course of investigative activities and initial operations and investigations can also be used both in proving and as evidence in court. When deciding on a sentence, the court, possessing exclusive powers of authority, verifies in a hearing the legitimacy of the information obtained by the parties of the criminal proceedings and ultimately resolves the dispute between them [10].

Block B: obtaining evidence during preliminary investigation. These are protocols of investigative activities, materials of initial operations and investigations obtained during operative support of the criminal case, materials form outside organizations (audit evidence, responses to investigator's requests, materials characterizing the defendant, etc.). This stage is when investigators make most errors, which are nonuniform and may have different degree of evaluation by the investigator oneself and the contending parties as well as by the court during the court investigation. Their structure is non-uniform and they can be distinguished into technical, methodological, and tactical errors. There are errors at the level of investigation strategy (incorrect definition of the direction of investigation, suggestion of theories, investigation planning in general) and at the level of tactics of executing a particular investigative or procedural activities (incorrect choice and use of tactics and forensic equipment in a particular investigation situation, failure to follow the optimal sequence of these activities). However, an investigator has the possibility to avoid errors at this stage by means of employing a broad range of various activities (receiving consultations from experts and assistance from lawyers; eliminating 
outside and inside counteraction; anticipating the possibility of loss of available exhibits; analyzing the available evidence to exclude particular ones on the grounds of inadmissibility, irrelevance, low power of evidence, and impossibility to make full use of due to operational interest or maintaining secrecy of investigation).

Block C: obtaining and evaluation of evidence during court investigation. This, first of all, includes using the evidence obtained during preliminary investigation, its validation and evaluation by the participants of court investigation; obtaining new evidence from the contending parties during court investigation; exclusion of evidence from legal proceedings. Since court proceedings are adversarial in their nature, this block of evidence can be represented by the following types of evidence: a) evidence offered by the public prosecutor: as a rule, the prosecutor uses the evidence collected during the preliminary investigation because, in the prosecutor's opinion, the evidence obtained by the prosecutor or made known to one after the end of the preliminary investigation can not be used in the court investigation; b) evidence offered by the defense: the evidence obtained in the course of the preliminary investigation with reference to breach of law; presenting the evidence obtained during the preliminary investigation but rejected and excluded by the investigator; new evidence, obtained by the defender oneself; c) evidence obtained in the initial operations and investigations during the litigation both in the preliminary investigation and in the supporting investigation during court proceedings; d) evidence obtained by the court itself as a result of performing investigative activities (the list of investigative activities carried out by the court is defined in the CCP of the RT).

The forensic content of the evidence is the information and data that serve to substantiate various circumstances that need to be proven and have significance for the case. However, unlike other types of evidence, this information is preserved in its original, unchanged, i.e. non-recoded form [11]. The results of our research allow us to make the conclusion that the substantiation of the internal conviction of the subject of proving in a criminal case to determine the objective truth is the information that is both objective truth and practically certain.

Establishing the truth in the process of preliminary investigation of criminal cases is carried out by proving the consequences, whose totality is the subject of investigation in a criminal case.

Given that, it is necessary to pay attention to the circumstance that visualizes the condition of the organizational support of employing forensic methods and equipment in crime scene investigation and also manifests in analyzing the results of this investigative activity, reflected in its protocols and criminal cases and compared with the results of interrogation of the persons convicted for committing crimes in these cases. Having carried out such kind of analysis, V.A. Volynskii assets that, in fact, 1 out of 4 material traces of crime left by criminals is actually extracted from the crime scene [12]. Effectively, this is the conclusion that P.P. Ishchenko comes to when noting that only one trace of crime is extracted in 5 cases of crime scene investigation for murders; handprints are in 1 out of 36 cases; and traces of blood, saliva, and sperm are in 1 out of 325 cases [13].

It should be noted that the data reported by the Forensic Center of the Ministry of Internal Affairs of the Russian Federation (hereafter FC MIA RF) indicate the same: from a single crime scene investigated by a forensic expert, an average of 1.08 of trace is collected. Speaking of the Republic of Tajikistan, this issue is critical, which is reflected in the studies of N.M. Samiev, who indicates the lack of specialists in crime scene investigations in cases when it is necessary as one of the reasons [14]. This way, $76 \%$ of the respondents among the employees of the preliminary investigation and interrogation in the Republic of Tajikistan indicated the reason to be the insufficient specialist staffing, $12.4 \%$ noted the reasons to be the failures to organize the cooperation between the investigation and forensics units, and 11.6 stated other reasons, for example the insufficiency of vehicles to make an operative response [14]. Furthermore, N.M. Samiev points out the fact that from the 450 criminal cases suspended in the proceedings due to failure to identify the person to be defendant or due to search of the suspect gone fugitive, crime scene investigation was only carried out in $58.8 \%$ of cases and involved a forensic expert only in $27.5 \%$ cases. That being said, it should be noted that forensic equipment was only used to investigate the scene of crime in $62.9 \%$ of cases, $43.1 \%$ of which was only photography. Research and development-based equipment was used to identify fingerprints in $17.3 \%$ of cases, to identify footprints in $1.5 \%$ of cases, to identify vehicle traces in $0.8 \%$ of cases, and to identify traces of blood, saliva, and other human bodily secretions it was used in $0 \%$ of cases [14]. A.L. Aripov notes at the same time that in the period from 2003 to 2009 , crime scene investigation was carried out in $88.8 \%$ of cases [15].

The aforementioned brings to the general conclusion: regardless of the previous decades that brought the improvement the state of equipment of the forensic units of the internal affairs agencies of the Republic of Tajikistan, the several-fold increase in their manpower, the efficiency of crime scene investigations, including the work of forensic experts, remains unchangeably low in the end.

In certain foreign countries where technical police and scientific ploce (i.e. forensic experts and specialists) are organizationally distinguished, standards of crime scene performance are 3-4 times higher [16]. There have been recorded instances when, for example, in Germany, around fifty different traces of crime were collected from one crime scene. A completely unique case that occurred in Finland is illustrative in this regard. This country's investigators detected and collected a swatted mosquito on a crime scene and used the blood inside it, subjecting it to DNA analysis and checking it against a corresponding database, to identify the person suspected of theft [17-19].

The results of analyzing the theory and practice of involvement of forensic specialists in crime scene 
investigations and the respective investigative research activities, its goals in concentrated but most generalized form can be represented in the following way: 1) identification, registration, and collection of material traces of crime; 2) identifying the mechanism of trace formation; 3 ) determining (recognizing) the nature of the trace substance and trace bearer; 4) reconstruction (restoration) of the detected objects: whole by parts; 5) collection (obtaining) of samples; 6) determining the possibility to identify the object; 7) studying the objects under investigation to obtain the desired data; 8) identifying cause-and-effect relations; 9) identifying temporal relations; 10) identifying the general mechanism and method of crime; 11) identifying attributes and characteristics of the person who committed the crime; 12) suggesting and validating theories; 13) compiling watch lists and briefing notes; 14) formulating suggestions in information and investigative documents; 15) ensuring the application of of forensic methods and tools; 16) simulating the attributes and characteristics of the person who committed the crime (the person's appearance) using the obtained traces; 17) assisting the operative in search and investigation activities; 18) assisting the investigator in describing traces and other objects collected during crime scene investigation; 19) checking the collected traces against criminal records; 20) assisting the investigator in professionally competent description of the process and result of investigative activities and collected crime traces; 21) assisting the investigator in packaging and ensuring the safety of the collected crime traces.

In order to present the complexity of the tasks solved by forensic experts on a crime scene in a more informative and clear way, it is necessary to consider the types of crimes and methods of committing them, the broad variety of traces of crime and other objects that must be dealt with, and, finally, the complexity (technical and functional) of the methods and tools that are applied when dealing with such tasks.

\section{Conclusion}

Based on the considerations stated above, it is possible to come to the main conclusion that this area and type of activity in solving and investigating crimes requires more deliberate attention in our country.

In a survey of graduates of the Expert Faculty of Volgograd Academy of MIA RF employed in the Expert-Criminalistics Department of the MIA of the Republic of Tajikistan, less than a half of them (44\%) could name the minimum list of tasks of a forensic expert's involvement in procedural actions that include 21 positions and almost a quarter of the respondents (23\%) confined themselves to mentioning around 5 positions.

Even worse in this regard are the organization and results of studying the specifics of crime scene investigation in law schools of the Republic of Tajikistan. The vast majority $(73 \%)$ of law school graduates consider that everything related to forensics during investigative activities is not investigators' and interrogators' concern, but only the job for forensics experts. It is obvious that such essentially "parasitical", incompetent attitude first of all contradicts the provisions of the CCP of the RT that determine the responsibility of investigators and interrogators for the results of evidence collection and, second, is untenable from the point of view of the modern capabilities of forensics units of the police to ensure the involvement in investigations of crime scenes of all registered crimes. It is no coincidence that one can more and more often hear suggestions from forensic experts acting as specialists about the necessity to limit their involvement in crime scene investigations with felonies and high crimes.

We consider this concern to be one of the most crucial issues in forensic support of crime scene investigations.

\section{References}

1. E.P. Ishchenko, Progress in science and technology as a determining factor in improving forensic equipment. Issues of development of forensics in the conditions of scientific and technological progress, (Sverdlovsk, 1982)

2. V.G. Kolomatskii, Background information of forensic support of criminal investigations. Information bulleting of the material of readings in forensics "Forensic support of fight against crime",. 13, 19-24 (2001)

3. R.S. Belkin, Forensic support of the activities of criminal police and preliminary investigation bodies ( Moscow: Novyi Iurist, 1997)

4. A.R. Rationov, Issues of cognition in court evidencing, Soviet state and law, 8 (1964)

5. Code of Criminal Procedure of the Republic of Tajikistan of 3 December 2009 No. 564 (ed. of 24 February 2017) Retrieved from: http://www.innovbusiness.ru/pravo/DocumShow_D ocumID_36351.html.

6. A.N. Gushchin, Initial operations and investigations: perfecting the forms of including its results in the criminal proceedings, (Moscow, 2003)

7. Code of Criminal Procedure of the RSFSR with materials pertaining to various articles 1960 (as amended on 24 January 1985). (Moscow: Iuridicheskaia literatura, 1987)

8. L.A. Voskobitova, Relations between the notions of "substantial breach of law of criminal procedure" and "admissibility of evidence", (Rostov-on-Don, 2007)

9. K.F. Gutsenko, Criminal procedure in the Western countries, (Moscow: Zertsalo-M, 2002)

10. A.S. Urgalkin, Admissibility of results of initial operations and investigations as evidence, Legislation and law, 8 (2010)

11. V.A. Lazareva, Issues of evidencing in the modern court proceedings, (Samara, 2007) 
12. V.A. Volynskii, Forensic technology. Science. Technology. Society. Human: a monography, (Moscow: UNITI. Legislation and law, 2000)

13. P.P. Ishchenko, Specialist in criminal activities (aspects of criminal procedure and forensics), (Moscow, 1990)

14. N.M. Samiev, Investigation of unsolved cases of the past years (study of materials from the Republic of Tajikistan and the Russian Federeation): Dissertation of PhD in Law, (Moscow, 2016)

15. A.L. Aripov, Investigator's activities to collect and validate evidence during preliminary investigation (study of law of the Republic of Tajikistan) Dissertation of PhD in Law, (Moscow, 2011)

16. G.V. Paramonova, I.N. Pervushina, About certain aspects of the tactics of involvement of forensic experts in crime scene investigation, Scholarly notes of the Faculty of Law,17 (27), 74-77 (2010)

17. Argumented facts, 20 - 2, 6 (January 2009)

18. B.M. Bishmanov, About the content of forensic support, Izvestiya Tula State University, Modern issues of Russian legislation, legal sciences, and law enforcement, 9, 42-44 (2003)

19. A.F. Volynskii, Forensic service of the MIA of Russia: the past, present, and future, Bulletin of the MIA of Russia, 3 (104), 76-83 (2009) 